\title{
Clinical and Radiographic Evaluation of Compomer and Composite used for Restoring Primary Teeth
}

\author{
Omar A. El Meligy 1,2, BDS, MSc, PhD and \\ Amani A. Al Tuwirqi ${ }^{1}$, MPhil, DClin Dent (Pediatric Dentistry) \\ ${ }^{1}$ Department of Pediatric Dentistry, Faculty of Dentistry \\ King Abdulaziz University, Jeddah, Saudi Arabia \\ ${ }^{2}$ Department of Pediatric Dentistry and Dental Public Health, Faculty of Dentistry \\ Alexandria University, Alexandria, Egypt
}

\section{Correspondence}

Prof. Omar A. El Meligy

Faculty of Dentistry

King Abdulaziz University

P.O. Box 80209, Jeddah 21589

Saudi Arabia

e.M: omeligy@kau.edu.sa

\section{Submission: 10 Mar. 2019 \\ Accepted: $\quad 26$ May 2019}

\section{Citation}

El Meligy OA, AI Tuwirqi AA. Clinical and radiographic evaluation of compomer and composite used for restoring primary teeth. JKAU Med Sci 2019; 26 (1): 37-49. DOI: 10.4197/ Med. 26-1.6

Copyright: (The Author(s), YEAR. Publisher. The Journal of King Abdualziz University - Medical Sciences is an Official Publication of "King Abdulaziz University". It is an open-access article distributed under the terms of the Creative Commons Attribution Non-Commercial License, which permit unrestricted non-commercial use, distribution, and reproduction in any medium, provided the original work is properly cited.

\begin{abstract}
This study assessed different restorative materials in primary teeth over a one-year period. Sixty carious primary molars were selected from 30 patients; ages 5-10 years. Class I and II cavities were divided into four groups: group I: 15 Class I cavities were restored with a compomer, group II: 15 Class I cavities were restored with a resin composite, group III: 15 Class II cavities were restored with a compomer and group IV: 15 Class II cavities were restored with a resin composite. Each child had two teeth restored, one with compomer and the other with composite resin as control. Direct clinical and radiographic evaluations were performed by one examiner after 24 hours, 6- and 12-months. Indirect clinical evaluations were performed using a Scanning Electron Microscope after 24 hours and 12-months periodically. Clinical and radiographic evaluations revealed no significant differences between the compomer and resin composite at 6- and 12-months. Indirect clinical evaluation showed good marginal interfaces between the restorations and the tooth structure throughout the evaluation periods. Both materials presented significant clinical and radiographic performances in Class I and II restorations of primary molars after one year.
\end{abstract}

\section{Keywords}

Compomer; Composite resin; Primary molars; Restoration

\section{Introduction}

significant amount of discussion still exists as to the most proper method to utilize in the treatment of decayed primary molars. Patient-related factors such as the ability to cooperate with the treatment with or without local anesthesia and adequate access to carious lesion, may both be compromised in the young and often apprehensive child. In these conditions, a restorative procedure should be fast and as easy as possible to reduce the treatment time. Yet the restoration should be durable enough to decrease the amount of re-treatment needed. Extreme longevity is not always necessary especially in primary molars with their limited life span ${ }^{[1]}$. 
The utilization of amalgam in restorations of primary teeth is popular and is confirmed by proof from clinical studies related to its strenght ${ }^{[2]}$. It was also a relatively technique insensitive material, particularly with respect to moisture contamination. These features may be helpful when restoring primary teeth in young children. Amalgam should be condensed in great quality as it was liable to break in narrow portions. This in addition with the necessity to include mechanical retention into the cavity preparation usually requires the sacrifice of healthy tooth structure during drilling of the tooth. Therefore, clinical studies of novel materials ${ }^{[3]}$ and methods for primary molars restoration should be compared with the specifications established by research into the strength and longevity of dental amalgam $^{[2]}$.

Since the early 1980 's, commercially available composite resins have evolved and new or improved products have been introduced continuously ${ }^{[4]}$. In the year 1983, the Council on Dental Materials, Instruments and Equipment (American Dental Association (ADA)) concluded that an acceptable resin based alternative for amalgam that can be utilized unconditionally as a restorative material for stress-bearing posterior restorations, was not presently obtainable ${ }^{[5]}$. At that time no composite resin material had been approved under the ADA's acceptance program. However, in the year 1993, six composite resin materials were accepted by ADA for use in posterior teeth, and many investigators and clinicians have recommended their use in class I and II cavity preparations when aesthetics is essential[6].

Polyacid-modified composite resins ("compomers") are mainly resin composites, with the difference that the resin monomers are adjusted to include acidic functional groups that have the ability to take part in an acid/base glass-ionomer reaction after resin polymerization has occurred ${ }^{[7]}$. This reaction leads to the release of fluoride. However, few compomers might have fluoride salts besides the fluoride release from the latter glass ionomer cement reaction, the total amount of fluoride released is notably less than that of conventional glass-ionomer cement or resin-modified glass-ionomer materials ${ }^{[8]}$.

Since compomers are mainly composite resins, they usually necessitate using primers and possibly adhesives before placing them in the cavity. These intermediate liquids permit the compomer to bond to the prepared cavity ${ }^{[9]}$. With some compomers, acid etching has been reported as an elective procedure. The primers and/or adhesives used before compomer restorations can include acidic components, that may produce enamel and dentin etching. In the primary dentition, it is likely that the utilization of compomers in their presently obtainable form without etching might be suitable. This may be because of the somewhat reduced amount of the primary tooth enamel mineralization compared with permanent tooth enamel. This dissimilarity may permit an efficient etch from some compomer primers ${ }^{[10]}$.

Compomers have been accepted with significant recognition, especially in pediatric dentistry. Their few steps in placement, great aesthetics, ease in manipulation, polymerization using light "commandcure", and other properties will make them user-friendly. Also, the current physical properties of compomers are described to be between the finest of any obtainable materials. Their physical properties approach those of composite resin, the most durable material reported so $\operatorname{far}^{[11,12]}$.

Reports of 6-, 12-, 24- and 36-month assessments of the clinical efficiency of Dyract as a dental filling in primary molars have been lately issued. Exact assessment outcomes using the Cvar and Ryge criteria, United States Public Health Service system and indirect replica techniques have revealed favorable conclusions. In these researches, baseline evaluations revealed restorations of outstanding quality. Postoperative sensitivity was not recorded at any time during the research follow-up period ${ }^{[13,14]}$.

The prosperity of compomers will probably remain for the expected time to come, mostly because of their ease in manipulation. Development of these materials in the coming future should lead to a more user-friendly product with enhanced properties ${ }^{[15]}$. The objective of this research was to assess for one-year different restorative materials in primary teeth.

\section{Materials and Methods}

The Faculty of Dentistry, Alexandria University Ethical Committee confirmed the research protocol.

\section{Study Design}

A controlled clinical trial was performed.

Thirty patients with sixty carious primary molars were chosen from the Out-Patient Clinic of the Pediatric 
Dentistry Department, Faculty of Dentistry, Alexandria University. Patients' age ranged from 5-10 years, each had two vital and symptomless carious primary molars that needed either Class I or Class II restorations. The patients were healthy and did not have any bruxism habit.

A compomer Dyract (Dentsply, DeTrey, Konstanz, Germany) and a resin composite Degufill H (Degussa, Frankfurt, Germany), were the materials used for restoration of Class I and Class II carious lesions. The cavities were divided into four groups: group I: 15 Class I cavities were restored with Dyract, group II: 15 Class I cavities were restored with Degufill $\mathrm{H}$, group III: 15 Class II cavities were restored with Dyract and group IV: 15 Class II cavities were restored with Degufill H. Each child had two teeth restored (either two Class I or two Class II restorations), one tooth was restored with a compomer and the other tooth with a resin composite as the control.

After administering local anesthesia and placing a rubber dam, Class I and Class II cavities were prepared using a No. 330 high-speed carbide bur. The cavity preparations were conservative and standard. The outline forms were kept to the minimum required for caries removal and adequate extension of the developmental grooves. The cavosurface margins were bevelled ${ }^{[16,17]}$. After selection of the proper shade for Dyract and Degufill $H$, the teeth were restored as stated by the manufacturers' recommendations.

\section{Tooth filling}

The cavities prepared were cleaned with water spray and excess moisture was removed with oil-free compressed air. Then, calcium hydroxide Dycal was applied to any deeply excavated areas of the cavities. For the Dyract restorations, a layer of the Dyract-PSA prime/adhesive was placed on the exposed dentin and enamel surface and kept untouched for 30 seconds. Extra solvent was removed with the air-syringe, then light cured for 10 seconds. To ensure complete coverage of the preparation, the second layer of DyractPSA prime/adhesive was placed according to the same process that was utilized for the first layer. Dyract was placed directly into the cavity using the manufacturer's recommended dispensing instrument. The material was placed in increments of $3 \mathrm{~mm}$ thickness or less and then each increment was light cured for 40 seconds to minimize polymerization shrinkage. For the Degufill H restorations, Degufill Etchant (37\% orthophosphoric acid) was applied to the whole cavity for 60 seconds, washed for 30 seconds, and then dried with oil-free compressed air. Bonding agent Degufill Bond was then placed on all cavity surfaces using a brush. The bonding agent was distributed with an oil-free air spray and then light cured for 20 seconds. Degufill H was dispensed directly into the cavity using a syringe. The material was placed in increments not more than $2 \mathrm{~mm}$ thick to minimize polymerization shrinkage. Each increment was light cured for at least 40 seconds. In the Class II restorations, a disposable celluloid matrix system, Hawe Neos (Hawe Neos Dental Bioggio, Switzerland) was used, which is a "cure-through squeeze" matrix system. The matrix system includes a soft metal ring, which tightens the clear band to the tooth when squeezed. This transparent band was applied around the teeth. A plastic wedge was also used in the cervical embrasure, whenever possible, to facilitate matrix adaptation. Following wedge and matrix removal, the restoration was exposed to the curing light through the lingual and buccal surfaces for an additional 40 seconds $^{[18]}$. Finally, the occlusion was checked, adjustments were made when necessary and final finishing was done using carbide finishing burs.

\section{Clinical Evaluation}

\section{a. Direct method}

Clinical evaluations of the restorations were performed using the criteria described by Cvar and Ryge ${ }^{[19]}$, after 24 hours (baseline), 6- and 12-months. The restorations were examined for anatomic form, marginal adaptation, color match and cavosurface marginal discoloration.

\section{Radiographic Evaluation}

Regarding evaluation of the proximal box, bite-wing radiographs were used. Radiographs were taken using a standard procedure, using a beam aiming device Rinn XCP extensive cone paralleling system (DENTSPLY Sirona, PA USA). The occlusal mount was achieved by applying self-polymerizing resin, using the imprints of the upper and lower teeth in the resin, bite blocks were then stored in water to prevent shrinkage ${ }^{[20]}$.

The bitewings were produced using a long cone X-ray unit 60 KVP, 10 MA (Yoshida Dental Mfg. Co., Ltd., Tokyo, Japan). The focus film distance was $25 \mathrm{~cm}$, exposure time was 0.8 seconds, using an electronic timer, after which, the radiographs were developed manually, using a developing time of 1-1.5 minutes at 
room temperature. Radiographic evaluation followed the items and criteria described by Kreulen et al. ${ }^{[20]}$.

\section{b. Indirect method}

A replica of the restored teeth was prepared periodically (7 of each material) in order to observe in detail changes which occurred in the marginal integrity of the restorations. Impressions "Lasticomp, Lastic 90" "Kettenbach Dental, Germany" of the filled teeth were taken after 24 hours (baseline) and at 12-month interval. These impressions were poured with an epoxy resin "Epofix, Copenhagen, Denmark" under vacuum and bench cured for 24 hours after which they were separated. The plastic models were covered with a fine gold layer about 0.03 um thick. The models were numbered and examined using a scanning electron microscope (SEM) to assess the marginal integrity of the restoration ${ }^{[21]}$.

Clinical and radiographic data were collected, tabulated and studied statistically. IBM SPSS Statistics for Windows, Version 20 (IBM Corp., Armonk, NY USA) was used for data scrutiny. Cochran-Mantel-Haenszel tests for ordered and binary categorical paired data were used to compare the materials for differences in clinical and radiographic evaluation parameters. For the clinical parameters, the tests were performed for all restorations combined and separately for Class I and II restorations.

\section{Results}

\section{Clinical Evaluation}

\section{a. Direct evaluation}

The clinical performance of 30 Class I and 30 Class II for both Dyract and Degufill $\mathrm{H}$ restorations was evaluated after 24 hours (baseline), 6 - and 12-months. At baseline, all restorations were intact and had the same category of rating "Alfa" for all criteria examined.

Table 1 shows the clinical evaluation of Class I for Dyract and Degufill $\mathrm{H}$ restorations at different evaluation periods.

After 6-month follow-up period, the percentage and number of Dyract fillings which were rated "Alfa" were 15 (100\%) restorations for anatomical form, 13 (87\%) restorations for color match, 15 (100\%) restorations for marginal adaptation, and 14 (93\%) restorations for marginal discoloration. Regarding color match, two (13\%) Dyract restorations were scored "Bravo". Whereas for marginal discoloration, one (7\%) Dyract restoration was scored "Bravo". The number and percentage of Degufill $\mathrm{H}$ restorations which were rated "Alfa" were $13(87 \%)$ restorations for anatomical form, color match and marginal discoloration. While for marginal adaptation, 12 (80\%) restorations were rated "Alfa". Regarding anatomical form, color match and marginal discoloration, only one (7\%) Degufill $\mathrm{H}$ restoration was rated "Bravo". Whereas for marginal adaptation, two (13\%) Degufill H restorations were rated "Bravo". One (7\%) Degufill H restoration was rated "Charlie" for anatomical form, color match and marginal discoloration, "Delta" for marginal adaptation.

At 12-month follow-up period, the percentage and number of Dyract fillings which were rated "Alfa" were $13(87 \%)$ restorations for anatomical form, color match and marginal adaptation. While for marginal discoloration, 10 (67\%) restorations were rated "Alfa". Regarding anatomical form, color match and marginal adaptation, two (13\%) Dyract restorations were rated "Bravo". Whereas for marginal discoloration, five (33\%) Dyract restorations were rated "Bravo". The number and percentage of Degufill $\mathrm{H}$ restorations which were rated "Alfa" were $12(80 \%)$ restorations for anatomical form, color match and marginal adaptation. While for marginal discoloration, 10 (67\%) restorations were rated "Alfa". Regarding anatomical form, color match and marginal adaptation, two (13\%) Degufill H restorations were rated "Bravo". Whereas for marginal discoloration, four (27\%) Degufill H restorations were rated "Bravo". One (7\%) Degufill H restoration was rated "Charlie" for anatomical form, color match and marginal discoloration, "Delta" for marginal adaptation.

Table 2 shows the clinical evaluation of Class II for Dyract and Degufill $\mathrm{H}$ restorations at different evaluation periods.

After 6-month follow-up period, the number and percentage of Dyract restorations which were rated "Alfa" were $13(87 \%)$ restorations for anatomical form, color match, marginal adaptation, and marginal discoloration. One (7\%) Dyract restoration was rated "Bravo", regarding anatomical form, color match, marginal adaptation and marginal discoloration. Another (7\%) restoration was rated "Charlie" for anatomical form, color match and marginal discoloration, "Delta" for marginal adaptation. The number and percentage of Degufill $\mathrm{H}$ restorations 

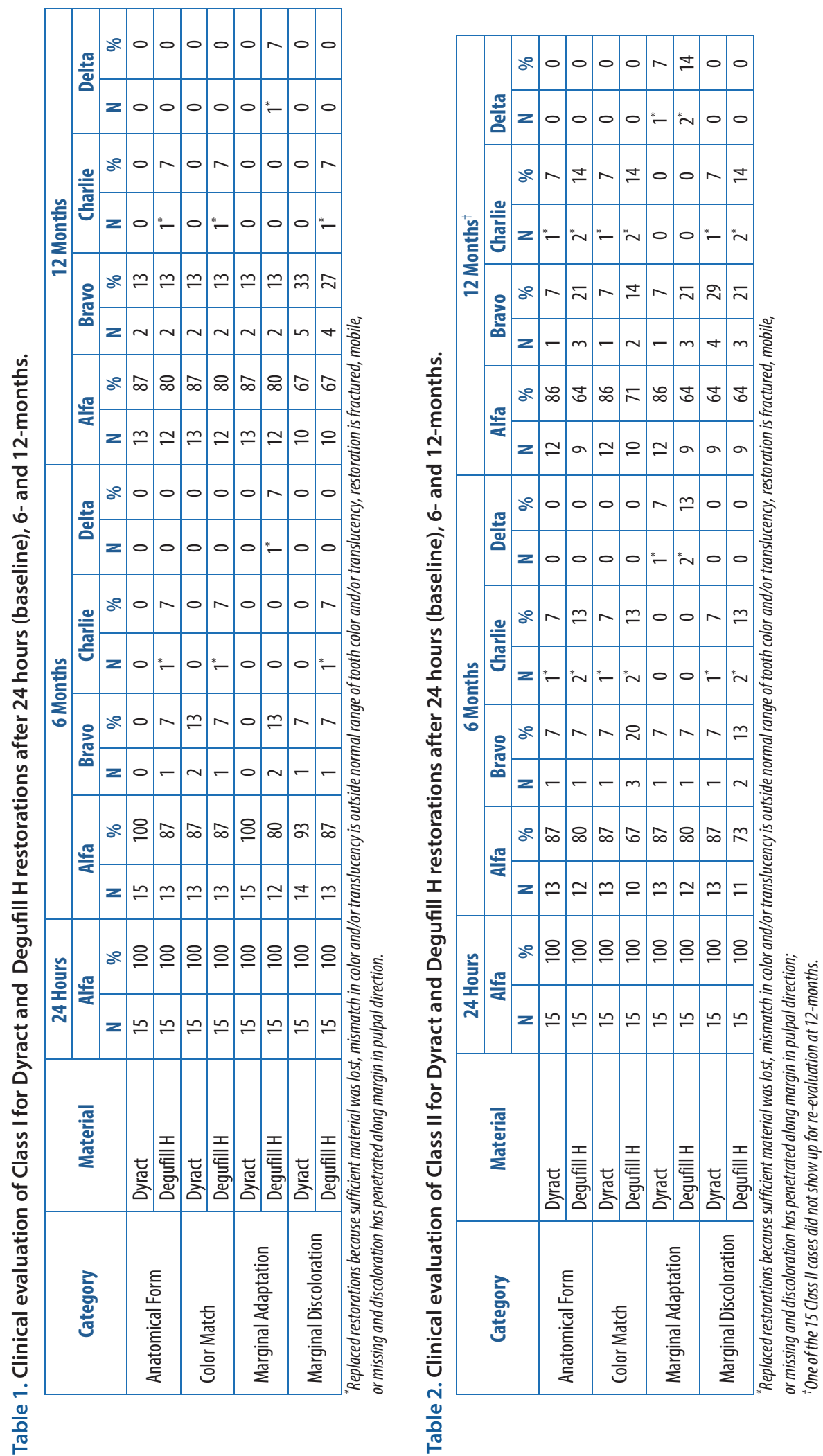
which were rated "Alfa" were $12(80 \%)$ restorations for anatomical form, 10 (67\%) restorations for color match, $12(80 \%)$ restorations for marginal adaptation, and 11 (73\%) restorations for marginal discoloration. Regarding anatomical form and marginal adaptation, only one (7\%) Degufill H restoration was rated "Bravo". Whereas for color match, three (20\%) restorations were scored "Bravo". While for marginal discoloration, two (13\%) restorations were rated "Bravo". Two (13\%) Degufill H restorations were rated "Charlie" for anatomical form, color match and marginal discoloration, "Delta" for marginal adaptation.

At 12-month follow-up period, it should be noted that two restorations (one Dyract and one Degufill H) failed to show up for re-evaluation. Therefore, the number and percentage of Dyract restorations, which were rated "Alfa" became 12 (86\%) restorations for anatomical form, color match, marginal adaptation. For marginal discoloration, nine (64\%) restorations were rated "Alfa". Regarding anatomical form, color match, marginal adaptation, only one (7\%) Dyract restoration was rated "Bravo". Whereas for marginal discoloration, four (29\%) restorations were scored "Bravo". Only one (7\%) Dyract restoration was scored "Charlie" for anatomical form, color match and marginal discoloration, "Delta" for marginal adaptation. The number and percentage of Degufill $\mathrm{H}$ restorations which were rated "Alfa" were nine (64\%) restorations for anatomical form, marginal adaptation and marginal discoloration. While for color match, 10 (7\%) restorations were rated "Alfa". Regarding anatomical form, marginal adaptation and marginal discoloration, three (21\%) Degufill H restorations were rated "Bravo". Whereas for color match, two (14\%) restorations were rated "Bravo". Two (14\%) Degufill H restorations were rated "Charlie" for anatomical form, color match and marginal discoloration, "Delta" for marginal adaptation.

Table 3 shows the clinical evaluation of Class I and II for Dyract and Degufill $\mathrm{H}$ restorations at different evaluation periods.

No notable differences were observed among Dyract and Degufill $H$ for any of the clinical parameters: anatomical form at 6 -months $(\mathrm{P}=0.18$ for Class $\mathrm{I}, \mathrm{P}=$ 0.53 for Class II, $P=0.20$ for all restorations), anatomical form at 12-months ( $P=0.41$ for Class $I, P=0.25$ for Class $\mathrm{II}, \mathrm{P}=0.16$ for all restorations), color match at 6 -months $(P=0.71$ for Class $I, P=0.25$ for Class II, $P=0.25$ for all restorations), color match at 12-months ( $P=0.41$ for Class I, $\mathrm{P}=0.37$ for Class II, $\mathrm{P}=0.23$ for all restorations), marginal adaptation at 6-months ( $\mathrm{P}=0.10$ for Class I, $\mathrm{P}$ $=0.53$ for Class II, $\mathrm{P}=0.13$ for all restorations), marginal adaptation at 12 -months ( $\mathrm{P}=0.41$ for Class $\mathrm{I}, \mathrm{P}=$ 0.25 for Class II, $P=0.16$ for all restorations), marginal discoloration at 6-months $(P=0.41$ for Class I, $P=0.37$ for Class II, $\mathrm{P}=0.23$ for all restorations), and marginal discoloration at 12-months $(P=0.74$ for Class $I, P=0.78$ for Class II, $\mathrm{P}=0.67$ ) for all restorations.

\section{Radiographic Evaluation}

Table 4 and Figure 1 show the radiographic evaluation of the proximal box for both Dyract and Degufill $\mathrm{H}$ restorations at different evaluation periods.

After 24 hours (baseline), all Dyract and Degufill $\mathrm{H}$ restorations showed good (Score 1) cervical margin adaptation and good (Score 1) step vertical wall adaptation.

After 6-month follow-up period, for Dyract, 13 (87\%) restorations showed good cervical margin adaptation, defects were seen in two (13\%) restorations, respectively. While in Degufill $\mathrm{H}, 10$ (67\%) restorations showed good cervical margin adaptation, defects were seen in five (33\%) restorations, respectively. Regarding step vertical wall adaptation, for Dyract, 14 (93\%) restorations showed good adaptation. In only one (7\%) restoration, respectively, adaptation was poor. For Degufill H, 12 (80\%) restorations showed good step vertical wall adaptation. In three (20\%) restorations, respectively, adaptation was poor.

At 12-month follow-up period, it should be noted that two restorations (one Dyract and one Degufill H) failed to show up for re-evaluation. Therefore, for Dyract, 10 (71\%) restorations showed good cervical margin adaptation, defects were seen in four (29\%) restorations, respectively. While in Degufill $\mathrm{H}$, eight (57\%) restorations showed good cervical margin adaptation, defects were seen in six $(43 \%)$ restorations, respectively. Regarding step vertical wall adaptation, for Dyract, 12 (86\%) restorations showed good adaptation. Only two (14\%) restorations, respectively, adaptation was poor. For Degufill H, 11 (79\%) restorations showed good step vertical wall adaptation. In three (21\%) restorations, respectively, adaptation was poor.

No notable differences were observed among Dyract and Degufill $\mathrm{H}$ for any of the radiographic Parameters: cervical margin adaptation at 6-months $(P$ $=0.26)$, cervical margin adaptation at 12 -months $(P=$ 

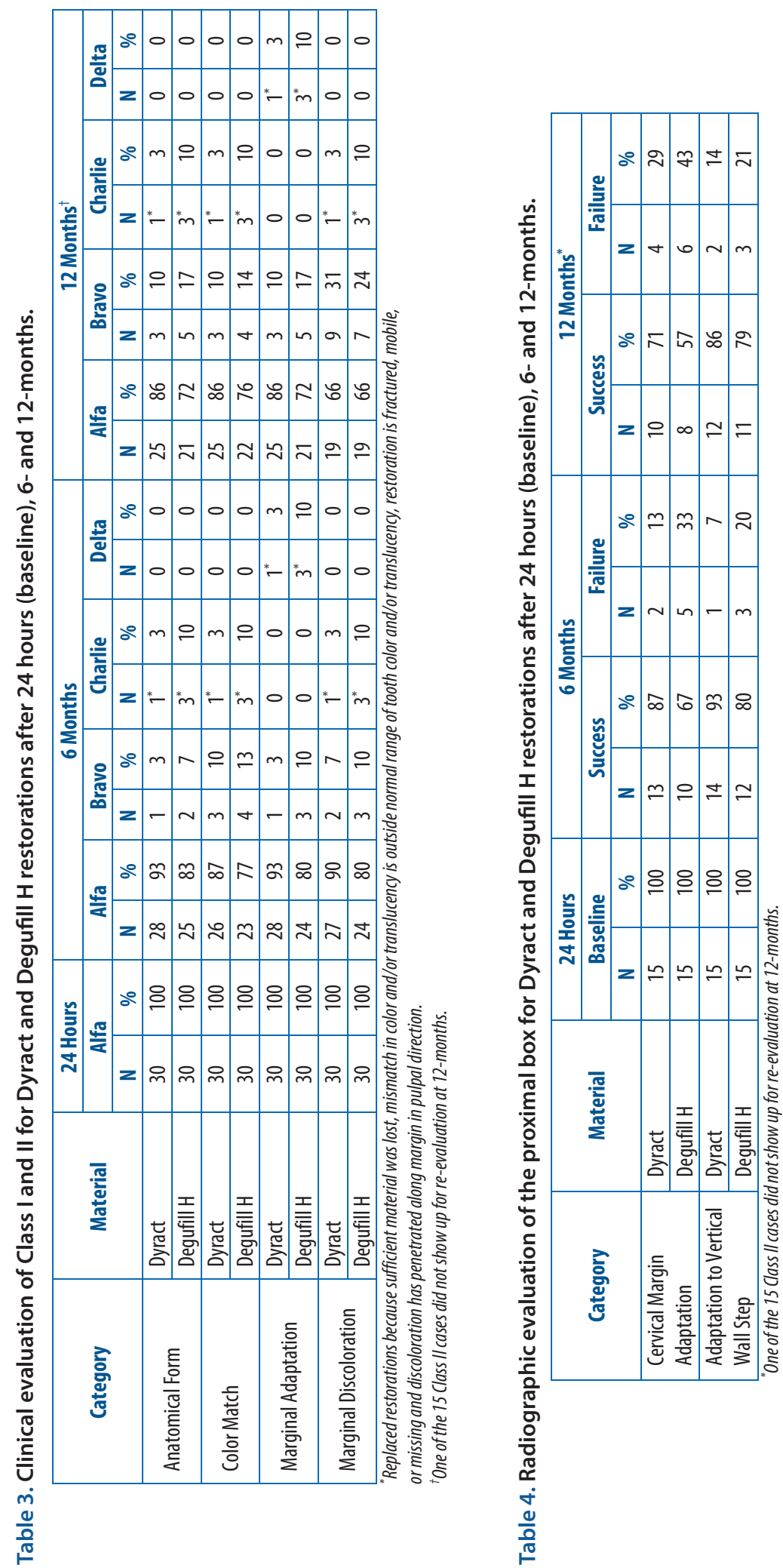


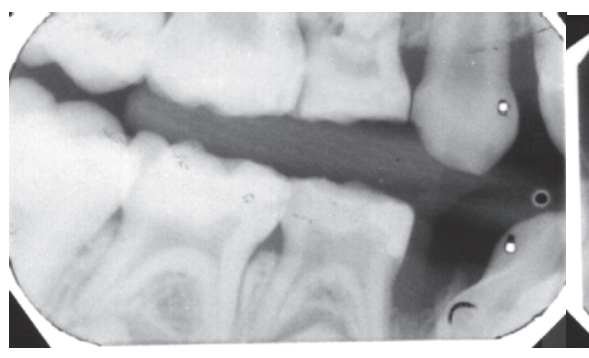

a

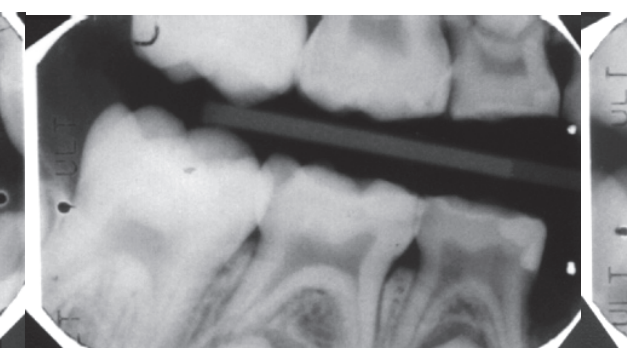

b

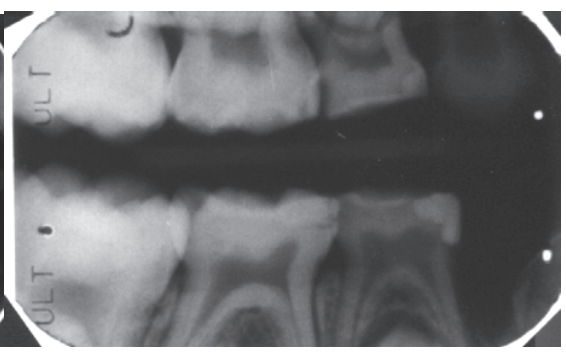

C

Figure 1a-c. Radiographs of occlusomesial restorations in lower right D Dyract and upper right $D$ Degufill $H$ showing good cervical margin adaptation and good step vertical wall adaptation, after 24 hours (baseline), 6- and 12-months.

0.41), adaptation to the vertical wall step at 6-months $(P=0.32)$, and adaptation to the vertical wall step at 12-months $(P=0.56)$.

\section{b. Indirect evaluation}

Scanning electron microscope examination of the replica of the restored teeth was utilized to assess the marginal integrity of the restorations after 24 hours (baseline) and at 12-months interval. The SEM photomicrographs are representing a good marginal interface between the tooth structure and the restorations throughout the evaluation periods (Fig. 2-5).

\section{Discussion}

The needs for a restoration in primary teeth are unlike from those in permanent teeth. This is because of the different levels of cooperation attained by youngsters, the short lifespan of the primary teeth and the variations in teeth morphology. Regarding primary teeth, the best restorative material should have excellent bonding characteristics and be easy to use, that will restrict the demand for an extended cavity ${ }^{[3]}$. The compomer utilized in our research satisfies these standards. Bonding is accomplished by use of a specific primer, that needs to be dried with air then cured with light. Phosphoric or polyacrylic acid needs washing and drying which makes it mandatory to completely isolate the tooth, resulting in a decreased possibility of contamination and a more pleasant technique for children. Since the compomer is provided in a compule, it could be placed directly into the prepared cavity, then light cured and finished ${ }^{[9]}$.

In our study, most of the Class I restorations of both Dyract and Degufill $\mathrm{H}$ retained good anatomical form

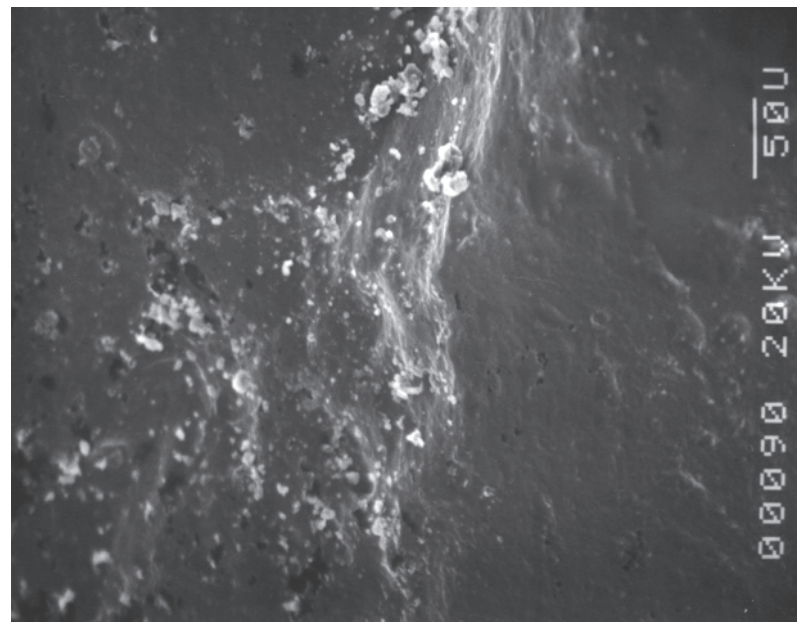

Figure 2. At baseline, scanning electron microscope photomicrograph of replica of Dyract restoration showing good marginal integrity between the Dyract and tooth structure.

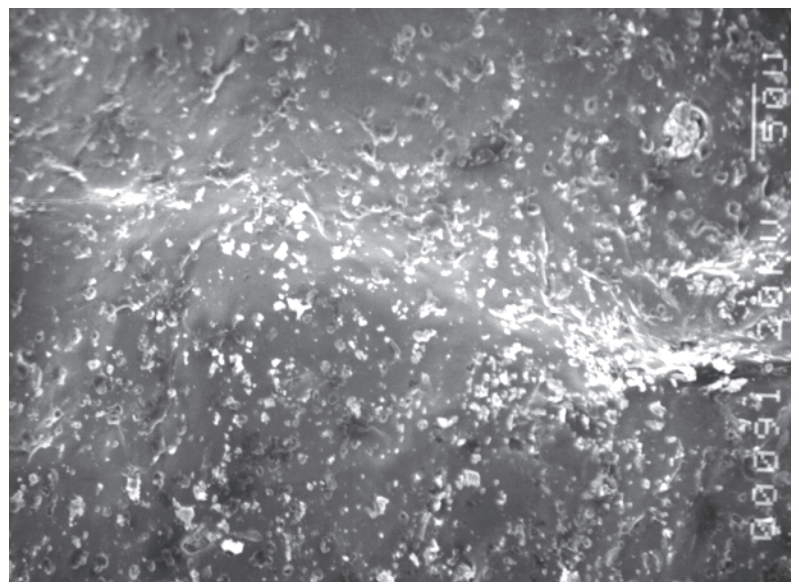

Figure 3. At 12-month recall, scanning electron microscope photomicrograph of replica of Dyract restoration showing good marginal interface between the Dyract and tooth structure. 


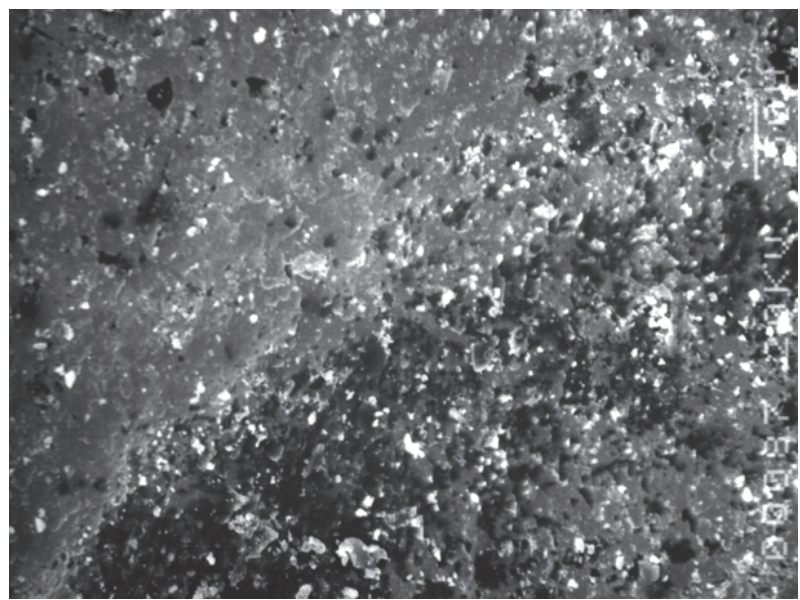

Figure 4. At baseline, scanning electron microscope photomicrograph of replica of Degufill $\mathrm{H}$ restoration showing good interface between the Degufill $\mathrm{H}$ and tooth structure.

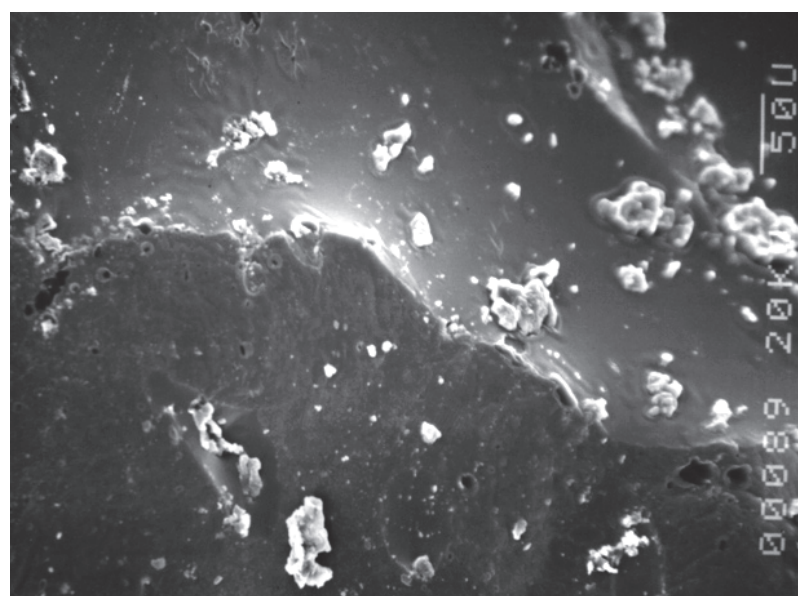

Figure 5. At 12-month recall, scanning electron microscope photomicrograph of replica of "Degufill $\mathrm{H}^{\text {" restoration }}$ showing good marginal integrity between the "Degufill $\mathrm{H}^{\text {" }}$ and tooth structure.

after the 6-and 12-month follow-up periods. The results for anatomical form were variable for both materials, $(100 \%, 87 \%)$, after 6 months and (87\%, 80\%) after 12 months, respectively, but not statistically significant. For Class II restorations, $87 \%$ and $86 \%$ of Dyract restorations were rated Alfa after 6- and 12-month follow-up periods, respectively. Whereas for Degufill $\mathrm{H}$, $80 \%$ and $64 \%$ of the restorations were rated Alfa after 6- and 12-month follow-up periods, respectively. A few restorations of both materials showed slight undercontouring attributed to masticatory wear.

Leinfelder et al. ${ }^{[22]}$ suggested that the slight undercontouring, which occurs on the surface of light-cured resin restorations, could be the result of microcracks created by finishing burs which weaken the surface of the material and make it less resistant to wear. Another suggested possibility is the minute surface irregularities, which create a condition of unequal stress distribution when in contact with antagonistic working cusps. In this study, carbide finishing burs were used as described by Yap et al. ${ }^{[23]}$. In another study, it was reported that aluminum oxide coated abrasive discs created less surface damage ${ }^{[24]}$.

The surface sealant was not used in the present study. It has been reported by Croll and Helpin ${ }^{[25]}$, that wear rates between restorations with or without surface sealants were not affected. However, Antonson et al. ${ }^{[26]}$ reported that sealant reduced microleakage in bevel margins.

At the 6- and 12-month follow-up periods, 13\% of Class I and 7\% of Class II Dyract restorations were given Bravo scorings for the color match because the restorations seem to be lighter than tooth structure in the cervical area. The greater opacity of Dyract compared with the natural tooth structure may interpret the Bravo recordings. This agrees with the findings obtained by Wucher et al. ${ }^{[14]}$. Furthermore, the translucent character of the Dyract makes the material very sensitive to influences of ambient light on the color match ${ }^{[9]}$.

A high percentage of Class I Dyract restorations retained good marginal adaptation at the 6- and 12 -month follow-up periods ( $100 \%$ and $87 \%)$, while only $80 \%$ of "Degufill $\mathrm{H}$ " restorations retained good marginal adaptation at the 6- and 12-month follow-up periods. However, there were no statistically significant differences between either material. For Class II restorations, $87 \%$ and $86 \%$ of Dyract restorations were rated Alfa at the 6- and 12-month follow-up periods, respectively. Whereas for Degufill $\mathrm{H}$ restorations, $80 \%$ and $64 \%$ of the restorations were rated Alfa, respectively. Therefore, the marginal adaptation of Dyract restorations appears to be comparable to those attained by Degufill H restorations utilizing enamel/ dentine bonding agents in Class I and II restored cavities. This agrees with the findings obtained by Pascon et al. ${ }^{[27]}$.

After 6-months, the percentage of Class I Dyract and Degufill $\mathrm{H}$ restorations that maintained an Alfa rating were $93 \%$ and $87 \%$, respectively, while only $67 \%$ of both restorations were rated Alfa after 12-months. 
For Class II restorations, $87 \%$ and $64 \%$ of Dyract restorations were rated Alfa after 6- and 12- months, respectively. Whereas, for Degufill $\mathrm{H}$ restorations only $64 \%$ of the restorations were rated Alfa after 6- and 12-months. There were no statistically significant differences between either material.

Marginal staining spots (probably of leakage), on the occlusal surface of Class I and II of both Dyract and Degufill $\mathrm{H}$ restorations, were detected in this study. The number of marginally stained teeth rise gradually for Dyract and Degufill $\mathrm{H}$ restorations, indicating continuous failure in the adaptation of the two restorations to the margins of the cavity.

In the present study, acid etching was not performed before Dyract was inserted (the manufacturers' instructions were followed). Without micromechanical retention, adhesion between the dental material and primer/adhesive with the tooth structures might not be powerful enough to preserve well sealed margins in all restorations especially where ideal conditions for adhesion are not accomplished ${ }^{[18]}$. Other researches have determined that increased bond strength for Dyract could be established when enamel etching is done prior to the application of the primer/adhesive ${ }^{[28,29]}$. Acid etching prior to placing the Dyract material should be considered to improve the adhesion and decrease microleakage when working under ideal conditions.

Failures observed with Class I Degufill H restorations (7\%) after 6-months, were the results of recurrent caries. The presence of secondary caries is most likely due to leakage. Adding fluoride to restorative materials may reduce the development of new carious lesions ${ }^{[8]}$. Failures observed with Class II Dyract restorations (7\%) and Class II Degufill H restorations (14\%) after 6-months were the results of fractures. These fractures were possibly caused by occlusal stresses of opposing cusps which could be avoided by proper adjustment of occlusal contacts or slight trimming of opposing cusps $^{[23]}$. The fractures of Class II Dyract restorations at the isthmus may also be the result of lower fracture toughness of Dyract compared to other materials ${ }^{[30]}$. Therefore, cavity design incorporating a shallow cavity with narrow isthmus should be avoided.

It should be pointed out that the whenever caries excavation was deep, the cavities were lined with a calcium hydroxide base to protect the pulp. There were no clinical signs of severe or irreversible pulpitis during this study.

Excess material could be left covering cavosurface margins as long as it does not interfere with occlusion, to assure coverage of all margins and can serve as a sealant ${ }^{[31]}$.

Clinical examination alone would not detect failures at the gingival margin. Kavvadia et al. ${ }^{[32]}$ stated that radiographs are necessary to assess the cervical margin adaptation of Class II restorations. In the present study, cervical margins had the greatest percentage of defects and they were identified with radiographs. The most frequent defects were crevices between the restoration and tooth or under-extended margins.

After 6-months, cervical defects were found in 13\% of the Dyract restorations and in 33\% of the Degufill $\mathrm{H}$ restorations. At 12-months, cervical defects were noted in $29 \%$ of the Dyract restorations and in $43 \%$ of the Degufill $\mathrm{H}$ restorations. It should be noted that one Dyract restoration and one Degufill $\mathrm{H}$ restoration were not available for assessment at 12-months. Defects at the cervical margins may have been due to either polymerization shrinkage, inadequate adaptation to the gingival wall, difficulty in placement at the proximal box, or shrinkage towards the light source. These problems have been observed in studies done by Varpio ${ }^{[17]}$, El-Mowafy et al. ${ }^{[33]}$ and Laegreid et al. ${ }^{[34]}$.

Deficient adaptation of the restorative material to the vertical wall of the step was seldom found, one Dyract and two Degufill H Class II restorations were mobile, fractured, restorations identified by clinical examination. The fractures may have been the result of high occlusal stresses, or they could have been the result of the poor adaptation of the material to the walls of the cavity.

Indirect clinical evaluations of marginal integrity were also conducted in this study using replicas technique and SEM. Visual observations of the interface between the restorative materials and the margins of the cavity preparations could be assessed. The SEM photomicrographs showed the good marginal interface between the tooth structure and the restorations throughout the evaluation periods (24 hours (baseline) and 12-months). Also, the microleakage evaluations revealed low mean scores for all the restorations (quantitative) and seem to correlate 
with the evaluations of marginal integrity (qualitative). These findings were confirmed by previous studies ${ }^{[21,35]}$.

\section{Conclusion}

Both the compomer and the resin composite presented significant clinical and radiographic performances in Class I and II restorations of primary molars after one year. More extensive follow-up is required to assess the longer-term performance of polyacid-modified composite resin.

\section{Conflicts of Interest}

The authors declare no conflict of interest.

\section{Disclosure}

The authors did not receive any type of commercial support either in forms of compensation or financial for this study. The authors have no financial interest in any of the products or devices, or drugs mentioned in this article.

\section{Ethical Approval}

Obtained.

\section{References}

[1] García-Godoy F. Resin-based composites and compomers in primary molars. Dent Clin North Am 2000; 44(3): 541570.

[2] Yengopal V, Harnekar SY, Patel N, Siegfried N. WITHDRAWN: Dental fillings for the treatment of caries in the primary dentition. Cochrane Database Syst Rev. 2016; 10: CD004483.

[3] Kilpatrick NM. Durability of restorations in primary molars. J Dent 1993; 21(2): 67-73.

[4] Demarco FF, Corrêa MB, Cenci MS, Moraes RR, Opdam NJ. Longevity of posterior composite restorations: not only a matter of materials. Dent Mater 2012; 28(1): 87-101.

[5] Phillips RW, Lutz F. Status report on posterior composites. Council on Dental Materials, Instruments and Equipment. J Am Dent Assoc 1983; 107(1): 74-76.

[6] Bohaty BS, Ye Q, Misra A, Sene F, Spencer P. Posterior composite restoration update: focus on factors influencing form and function. Clin Cosmet Investig Dent 2013; 5: 3342.

[7] Nicholson JW. Polyacid-modified composite resins ("compomers") and their use in clinical dentistry. Dent Mater 2007; 23(5): 615-622.

[8] Burke FM, Ray NJ, McConnell RJ. Fluoride-containing restorative materials. Int Dent J 2006; 56(1): 33-43.
[9] Moodley D, Grobler SR. Compomers: adhesion and setting reactions. SADJ 2003; 58(1): 21, 24-8.

[10] Kugel G, Perry RD, Hoang E, Hoang T, Ferrari M. Dyract compomer: comparison of total-etch vs. no etch technique. Gen Dent 1998; 46(6): 604-606.

[11] Berg JH. The continuum of restorative materials in pediatric dentistry-a review for the clinician. Pediatr Dent 1998; 20(2): 93-100.

[12] Attin T, Opatowski A, Meyer C, Zingg-Meyer B, Buchalla W, Mönting JS. Three-year follow up assessment of Class II restorations in primary molars with a polyacid-modified composite resin and a hybrid composite. Am J Dent 2001; 14(3): 148-152.

[13] Peters TC, Roeters JJ, Frankenmolen FW: Clinical evaluation of Dyract in primary molars: 1-year results. Am J Dent 1996; 9 (2): 83-88.

[14] Wucher M, Grobler SR, Senekal PJ. A 3-year clinical evaluation of a compomer, a composite and a compomer/ composite (sandwich) in class II restorations. Am J Dent 2002; 15(4): 274-278.

[15] Burke FJ, Fleming GJ, Owen FJ, Watson DJ. Materials for restoration of primary teeth: 2 . Glass ionomer derivatives and compomers. Dent Update 2002; 29(1): 10-14.

[16] Swanson TK, Feigal RJ, Tantbirojn D, Hodges JS. Effect of adhesive systems and bevel on enamel margin integrity in primary and permanent teeth. Pediatr Dent 2008; 30(2): 134-140.

[17] Varpio M. Proximo-occlusal composite restorations in primary molars: a six-year follow-up. ASDC J Dent Child 1985; 52(6): 435-440

[18] Hse KM, Wei SH. Clinical evaluation of compomer in primary teeth: 1-year results. J Am Dent Assoc 1997; 128(8): 1088-1096.

[19] Cvar JF, Ryge G. Reprint of criteria for the clinical evaluation of dental restorative materials. 1971. Clin Oral Investig 2005; 9(4): 215-232.

[20] Kreulen CM, van Amerongen WE, Akerboom HB, Borgmeijer PJ, Gruythuysen RJ. Radiographic assessments of Class II resin composite restorations in a clinical study: Baseline results. ASDC J Dent Child 1992; 59(2): 97-107.

[21] Luo Y, Tay FR, Lo EC, Wei SH. Marginal adaptation of a new compomer under different conditioning methods. J Dent 2000; 28(7): 495-500.

[22] Leinfelder KF, Wilder AD Jr, Teixeira LC. Wear rates of posterior composite resin. J Am Dent Assoc 1986; 112(6): 829-833.

[23] Yap AU, Yap SH, Teo CK, Ng JJ. Finishing/polishing of composite and compomer restoratives: effectiveness of one-step systems. Oper Dent 2004; 29(3): 275-279.

[24] Barbosa SH, Zanata RL, Navarro MF, Nunes OB. Effect of different finishing and polishing techniques on the surface 


\section{Evaluation of Two Materials Used for Primary Teeth \\ O.A. El Meligy and A.A. Al Tuwirqi}

roughness of microfilled, hybrid and packable composite resins. Braz Dent J 2005; 16(1): 39-44.

[25] Croll TP, Helpin ML. Class II Vitremer restoration of primary molars. ASDC J Dent Child 1995; 62(1): 17-21.

[26] Antonson SA, Yazici AR, Okte Z, Villalta P, Antonson $D E$, Hardigan PC. Effect of resealing on microleakage of resin composite restorations in relationship to margin design and composite type. Eur J Dent 2012;6(4): 389-395.

[27] Pascon FM, Kantovitz KR, Caldo-Teixeira AS, Borges AF, Silva TN, Puppin-Rontani RM, Garcia-Godoy F. Clinical evaluation of composite and compomer restorations in primary teeth: 24-month results. J Dent 2006; 34(6): 381-388.

[28] Tate WH, You C, Powers JM. Bond strength of compomers to human enamel. Oper Dent 2000; 25(4): 283-291.

[29] Baghdadi ZD. Bond strengths of Dyract AP compomer material to dentin of permanent and primary molars: phosphoric acid versus non-rinse conditioner. J Dent Child (Chic) 2003; 70(2): 145-152

[30] Ilie N, Hickel R, Valceanu AS, Huth KC. Fracture toughness of dental restorative materials. Clin Oral Investig 2012; 16(2): 489-498.

[31] Hilton TJ. Can modern restorative procedures and materials reliably seal cavities? In vitro investigations. Part 1. Am J Dent 2002; 15(3): 198-210.

[32] Kavvadia K, Kakaboura A, Vanderas AP, Papagiannoulis L. Clinical evaluation of a compomer and an amalgam primary teeth class II restorations: a 2-year comparative study. Pediatr Dent 2004; 26(3): 245-250.

[33] El-Mowafy O, El-Badrawy W, Eltanty A, Abbasi K, Habib N. Gingival microleakage of Class II resin composite restorations with fiber inserts. Oper Dent 2007; 32(3): 298305

[34] Laegreid T, Gjerdet NR, Vult von Steyern P, Johansson AK. Class II composite restorations: importance of cervical enamel in vitro. Oper Dent 2011; 36(2): 187-195.

[35] Ayna B, Celenk S, Atas O, Tümen EC, Uysal E, Toptanci IR. Microleakage of glass ionomer based restorative materials in primary teeth: An In vitro study. Niger J Clin Pract 2018; 21(8): 1034-1037. 


\title{
تقييم سريري واشعاعي للكومبومر ومركب الراتنج المستخدم لحثو الأسنان اللبنية
}

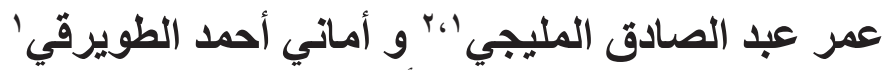

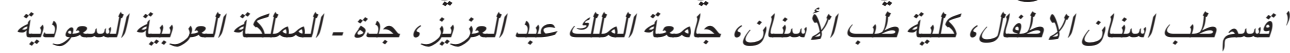

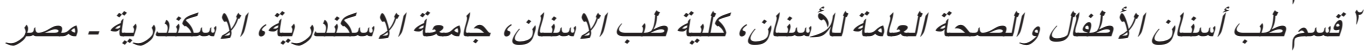

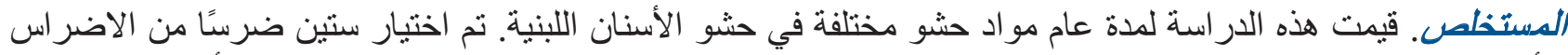

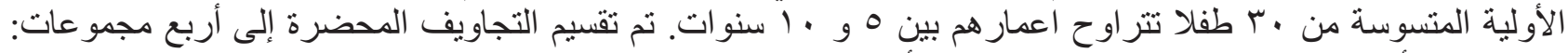

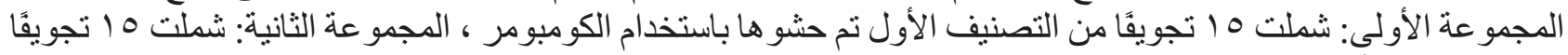

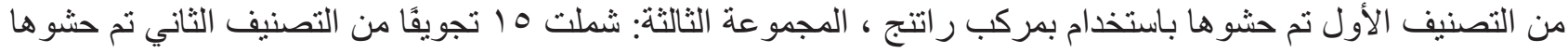

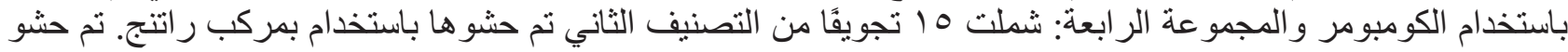

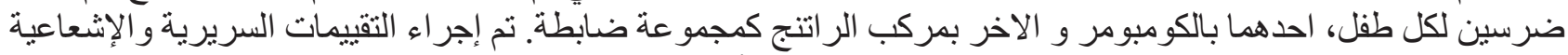

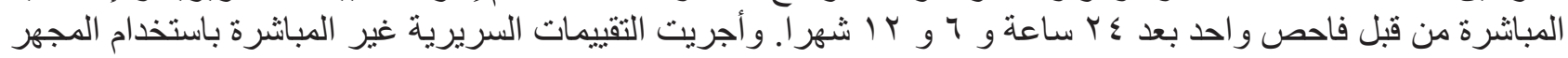

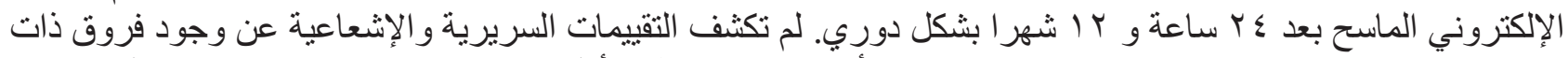

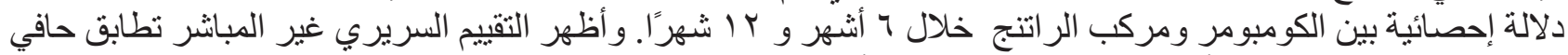

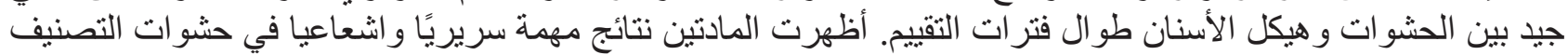
الأول و الثاني من الأضر اس اللبنية بعد عام. 